\title{
PEDAGOGICAL NOTION OF (DIS)CONTINUITY IN LEARNING AND ITS CRITICAL - PEDAGOGICAL POTENTIAL
}

\begin{abstract}
The goal of this paper is to research the pedagogical notion of discontinuity in learning, its pedagogical importance and discover the notion of pedagogical subject that is complementary to it. Discontinuity is closely related to the idea of negativity in its existential sense. Discontinuity and negativity in learning are investigated in their various forms and meanings, in order to understand the pedagogical approach to these phaenomena. Our approach is differentiated by approaches based on "school success", since pedagogical authors such as J.F. Herbart, J. Dewey and A. English see negativity and its pedagogical potential in an existential sense. Based on these insights, we further ask which kind of pedagogical subject can embody discontinuity and negativity in learning. We find that specific ideas of (critical) theory, (dialectical) knowledge and (critical) subject are needed for that. These ideas open often unexplored possibilities for pedagogical theory and practice.
\end{abstract}

Keywords: discontinuity, negativity, learning, pedagogy, critical subject, critical theory.

\section{Introduction}

We all encounter negative emotions and feelings in our day-to-day life: it is the unavoidable part of human experience. This is especially evident in a learning environment, that being mostly our work or school environment. Suggestion of seeing negativity of learning as a positive and moreover as a crucial part of

* Magdalena Mišić, mag. paed. and mag. philol. bohem., University of Zagreb, Faculty of Humanities and Social Sciences, Department of Pedagogy.

** Zvonimir Komar, doc. dr. sc., University of Zagreb, Faculty of Humanities and Social Sciences, Department of Pedagogy; e-mail: z komar@ffzg.hr. 
the learning and teaching process in education, was argued by Andrea English (2013) in her work Discontinuity in learning: Dewey, Herbart, and Education as Transformation.

In the first part of this paper, we discuss the terminology used in pedagogy when talking about negativity in experience. After that, we will try to introduce the notion of discontinuity in learning into the pedagogical context, in the way that was already explained by A. English and compare it to the recent studies about failure-based learning designs, explaining how majority of mentioned designs gathered around "failure" and "success" are hindering the pedagogical subject to be truly transformed. Our goal with the second part of paper is to (here at least theoretically) articulate the specific notion of pedagogical subject that can utilize these practices of negativity and discontinuity to develop him/herself in an existential and transformative way and use these ideas not only for the sake of "success" in learning. Based on this, we will argue that the idea of discontinuity is an essential part and a way to pedagogically construct a critical-pedagogical subject. To be able to do that, we will engage deeply into the critical-philosophical discussion of the critical theory itself, and at the end, offer a final summary to our paper in the light of the future pedagogical theory and practice.

\section{Terminology usage}

Before engaging into the discussion of discontinuity in learning, we would like to quickly comment on the terminology usage regarding the negativity of learning as presented in this paper. Negativity of learning experience as such is not a new phenomenon in pedagogical context, but it is hardly enough explored, theorized, or empirically researched. In German speaking pedagogical areas, it is mostly referred to as Negativität im Unterricht (Negativity in class) or Negativität der Erfahrung (Negativity of experience) (Benner, 2005, Schluß, 2005, English, 2013). In English speaking pedagogical areas, we can also find the usage of Negativity of learning and Negativity of experience, but those are at most times overlapping with psychological research and articles. As a prominent reason why the term negativity and its philosophical and critical-pedagogical potential is being pushed to the side, Andrea English sees in its pejorative effect on English speakers, especially to the "English language philosophical discourse" (English, 2013: XXI). The English language terminology that is connected to negativity of learning in pedagogical sense is mainly focused around problem-solving or failure-based pedagogical designs, which are aiming at the instructional aspect of learning and teaching in education. Those will be reviewed and discussed in more detail in later sections of this paper. 


\section{Discontinuity in Learning}

Due to common perception of negative experience in learning and teaching as being something $\mathrm{bad}$, Andrea English tried to find new ways how to express negative educational processes so that its pedagogical merit would not be easily overlooked: "By examining connections between negativity and learning, we can open up the possibility of grasping meaningful difference between learning as a mere correction of error and learning as transformation of self and world." (English, 2013: XXII).

For that reason, she coined a concept of discontinuity in learning, by which every blockage, gap or contradiction experienced during a learning and teaching process is meant. These "discontinuous moments" are visible to us as a variety of emotions - from ignorance, frustration, confusion to doubt. In our own experience, we have surely come to know how learning and teaching are not always positive and continuous, and what English wanted to emphasize is that moments of discontinuity and negativity are not only beneficial, but also "constitutive of learning processes" (ibid: 13).

Importance of discontinuity could already be found in work by some of the greatest pedagogical minds like J.F. Herbart and John Dewey. Although Herbart never explicitly mentioned negativity and discontinuity, a moment of interruption in the process of learning was a crucial part of his moral education (ibid). An interruption presents a catalyst for doubting what one knows (or think she/he knows) and it allows one to distance herself/himself from itself in viewing the world with new eyes, enabling the process of what Herbart calls Bildsamkeit (perfectability or educability), an ability and need of a human to continuously learn and change. On the other hand, Dewey did theorize continuity and discontinuity in learning in terms of what he calls reflective experience. That kind of experience is triggered by undergoing (or passively receiving) the world in the form of interruptions in which previous knowledge and ability comes to question. It happens by breaking out from the world one has known up till now and reflecting upon one's relation to this new world. In that way, "reflective thinking, for Dewey, creates a connection or continuity out of what was directly experienced as discontinuous and disconnected." (ibid: 69).

\section{In-between Realm of Learning and Two Beginnings of Learning}

To experience negativity, therefore, means to experience something unknown, something that one perceives as the Other and Otherness in comparison to oneself. Furthermore, it allows one to re-construct its known world and mindset, existing structure of thought, previously learned concepts and processes and to implement them into a transformed new self. This transformation happens in a transitional space that lies beyond one's limits, a space that English calls in-between realm of learning: "This opening is an educational space in which the learner finds herself 
bound up in a realm that lies between an encounter with the limits of knowledge and ability, and the new knowledge or ability that is yet to be found." (ibid: 25)

As English mentioned, in the transitional space there is something yet to be found, and while being in the space one did not yet think of a way to solve the problem of the experienced interruption. To understand the process of being in the in-between realm of learning, we need to be aware that Dewey made a distinction between the moment of interruption (what he called perplexity, confusion, and doubt) and a moment when reflective processes take place. This will also be important later in the paper when we are discussing problem-solving pedagogical designs in education. One's reflection processes do not start with one's recognition of a problem to be solved, but with the experience of interruption, which English marks as prereflective beginnings (by Dewey: prereflective situations of our experience). Prereflective beginnings is the first beginning of learning, because "the learner finds herself in an indeterminate situation" (caused by the interruption), and the second one is reflective-transformative beginnings, in whichlearner creates a "problematic situation" out of what was only an uncertain "indeterminate situation" (ibid: 76-77).

\section{In-between Teaching and a Classroom as a Space for Interrupting Experience}

Since an interruption can only have its learning and teaching potential once it is used as an opening for reflective experience, many interruptions can be easily overlooked by learners and teachers. For that reason, in-between teaching requires a teacher to create, recognize and initiate interruptions experienced by learners and to support them in inquiring and exploring it deeper, which would lead them to reflect on them and subsequently to search for a way to resolve them. According to Dewey, teachers also have an important role to prolong the time spent in the in-between realm of learning as much it is needed: “...It is essential for learners to reside in the in-between for the sake of their own learning process: it is in this space that learners can find possibilities for experimenting with the new and, on that basis, develop new learning experiences." (ibid: 55)

In this way a classroom becomes, what English calls, a space of interrupting experience, a "space for discovering at what point a student will be interrupted in his or her reaction with the new objects and ideas encountered herein." (ibid: 89). As this process is an in-between learning process situation for a learner, it is also an in-between teaching situation for a teacher, in which she or he goes through a reflective experience in a relation to a student's reflective experience.

Fundamentally, teachers experience discontinuity in learning themselves. They have come across it throughout their whole life, starting from their own professional education to their professional work inside the classroom, that being not always directly connected to learners' moments of discontinuity. According to Dietrich Benner, teachers perceive their own moments of difficulty not in the same way as 
they would see difficulties of their learners: "They therefore notice experiences of strangeness and disappointment more in themselves and in their own actions and less in the adolescents whose learning processes they seek to support and encourage." (Benner, 2005: 9)

Moreover, since interruptions in learning are something familiar to them, they often tend to overlook or not recognize it by their students. This also happens because of the unavoidable nature of the negative experience in learning: after we overcome it, we are forgetting it. Benner compared it to a child that is growing up: a walking toddler cannot learn to walk again after it has once learned it and cannot remember anymore how it was not knowing how to walk (ibid: 10). Nonetheless, what one once learns, serves as a base for further learning: "We continue to learn based on what we have already learned and therefore cannot learn again what we have already learned. Essential part of learning is that what has been learned once, can be at best un-learned in pieces, but not re-learned a second time." (ibid: 11)

Teachers, therefore, forget how it was to not know a certain topic or a subject, but remembering can help them understand how it is currently happening for their students. Through remembering, they are not able to re-learn what they have already learned but can manage to reflect on their experience with new eyes (ibid: 14). Besides, it also gives teachers a role to navigate not only negative experience of others, but also negative experiences of themselves, which requires a certain sensibility: "Receptivity to learning experiences is tied back to a pedagogical sensitivity that allows professional educators to perceive and observe the formative function of negative experiences in themselves and others." (ibid: 14)

This teacher role corresponds to the mentioned in-between teaching and a classroom as a space of interruption by Andrea English and re-confirms an inevitable truth of learning and teaching processes being complex, discontinuous, and hard. It also consolidates the idea that struggle and interruptions are constitutive of learning and teaching to become truly transformative.

\section{Benner's notion of Nicht-Wissen and Wissen in learning}

When talking about negative experience in learning in paper Über pädagogisch relevante und erziehungswissenschaftlich fruchtbare Aspekte der Negativität menschlicher Erfahrung, Dietrich Benner (2005) discussed the already established logic of learning process: the journey from the point where we do not yet know, to the point where we already know. Even though it is somewhat helpful and easy to picture the learning process that way, according to him, succession of yet to already is wrongly perceived as a "jump" from one side to another. Namely, as he explains, the notion of knowing and not knowing (Wissen und Nicht-Wissen), to be capable and to be not-capable (Können und Nicht-Können) are at most times actually happening at the same time, intertwined: "In learning processes, however, learners do not simply move from a not-knowing to a knowing, from a not-capable 
to a capable, but in an in-between space that is bounded in all directions by knowing and not-knowing, capable and not-capable." (Benner, 2015: 8). In this sense, all that we know meets all that we do not know, and in doing so, something foreign does not take place of something familiar, but one is supplementing the other throughout the constant dichotomy play of knowing and not knowing: "The transformational process is rather determined by the fact that something unknown is experienced in something known, and that the unknown is in certain aspects already known." (Benner, 2015: 9) This is what takes negativity in the learning process to an existential level, because just being means to constantly know and not to know at the same time.

This brings us back to the J.F. Herbart and J. Dewey and their own view of the true meaning of education, and its connection to the experience of negativity and struggle. For J.F. Herbart this constant inner struggle (Inner Kampf) is a way for a moral human being to reach inner freedom (Innere Freiheit), and the learning process itself is a way for one to become a self-determined autonomous individual (English, 2013: 8-9). J. Dewey, for whom human experience was a reflective experience, argues that a negative experience in learning (confusion, doubts, perplexities) is essential for a human being to reflect upon the world: to understand itself and its relation to the world, to make decisions and act, gradually becoming a selfdeterminate and self-critical individual, living in a democratic society (ibid, 65, 101-102). We can notice how discontinuity in learning is inevitably connected to the basic questions of education, meaning of education, and meaning of the bare human existence itself.

\section{Four forms of negativity of learning}

In the light of pedagogical importance of negative experience in education, in the following section we will present four distinctive forms of negativity (Vier Formen von Negativität) by Henning Schluß, which in my opinion comply with the concept of discontinuity in learning in their basic thought:

- Negative experiences can be experiences that do not fit into the learners' previous, already acquired horizon of experience and thus stand out or differ from it.

- Negative experiences can be bad experiences that learners interpret as adverse experiences by experiencing ill-will or injustice. Such experiences can have the character of categorically bad or evil in the experiencer's interpretation.

- Negative experiences can also be those that learners have in their dealings with persons related to education, who have acted in a way that seems undesirable to them, are denying those expressions of learners and are seeking to transform them into so-called desirable or positive behavior.

- Negative experiences can ultimately be associated with a painful reversal in which previous understandings, expectations and concepts of action 
are questioned and problematized in such a way that they appear to need correction. (Schluß, 2005: 183)

We can see that the above distinctive forms of negativity implicate the aspect of learning being an interruptive experience for learners, in which they encounter Other and Otherness, and find the urge to change their abilities acquired up till now, to overcome them. This distinction appreciates the negativity in experience as something that is prereflective, meaning that it is happening before the one's recognition of a problem, and not only by trying to solve already set problemsolving tasks. Third form of negativity acknowledges the relation of the learner towards the teacher and other students and starts a topic regarding the teacher as an equal participant of the process. Even though Schluß doesn't explicitly point out how both teacher and student are the ones experiencing negativity, his mentioning of teacher's "denying of negative expressions" and need to "transform them into so-called desirable or positive behavior", speaks of a teacher who is overlooking a learner's interruption and its potential opening for learner's reflective, transformative experience.

\section{Failure-based Learning Designs}

In their paper Failing to learn: towards a unified design approach for failurebased learning Tawfik, Rong and Choi (2015) are inquiring into six failure-based learning designs and are suggesting their own failure-based pedagogical designs, as a combination of the ones they researched. They looked through Piaget's cognitive disequilibrium, impasse driven learning, productive failure, failure-driven memory in case based reasoning and negative knowledge in workplace learning. In the following section we will briefly summarize each design, before putting them in a relation to the notion of discontinuity in learning.

For the most part, designs are founded on the psychological and cognitive experiments of the learning experience and acknowledge the moment of failure, error, or perturbations as constitutive of learning. For Piaget, interruptions are marked as "perturbations" that are causing a cognitive "disequilibrium", which one should overcome to reach a new schema of an "equilibrative state" (Piaget, 1977, as cited in Tawfik et al., 2015: 977). In impasse driven learning, learner experiences a form of interruption marked as "impasse", that can also be experienced as an "uncertainty during a learning task", and a teacher's role would be to create openings for experiencing the "impasse" (Brown and VanLehn 1980, Jones and VanLehn 1994, VanLehn et al. 2003, as cited in Tawfik et al., 2015: 979). This kind of design advocates creating impasse for a learner to inquire more and subsequently, restructure its cognitive system for better learning outcomes (ibid). Failure-driven memory in case based reasoning argues that experience of failure helps with creating a new path in memory "that serves as a new foundation for future problem-solving" (Schank 1999, as cited in Tawfik et al., 2015: 980). Negative knowledge in workplace learning gives 
importance to the failure experienced at work, claiming that analyzing the failure helps workers to seek better strategies and solutions with every next problematic encounter (Gartmeier et al., 2008, as cited in Tawfik et al., 2015). Productive failure design created by Manu Kapur suggests creating an opening for learner's failure by "delaying support" during the learning experience. He also conducted several empirical researches on productivity of failure, which all resulted in favor of it (Kapur 2008, 2010, 2011, as cited in Tawfik et al., 2015, Song and Kapur, 2017). Kapur sees the "delay of support" as a way of engaging students in what he calls "unguided problem" - a problem that they need to solve for themselves, with the minimum help of a teacher (Song and Kapur, 2017).

Kapur's mention of "delaying of support" and "unguided problem" are what Tawfik and colleagues refer to as ill-defined problems in the learning process. They recognize a distinction between well- and ill-defined problems and solutions in the research of problem-solving designs. For them, ill-defined problems possess "multiple solutions", and as they offer more complexity, uncertainty and autonomy to a learner, this can result in learner's better "reflection upon failures" (Tawfik et al., 2015: 976). Somewhat similar distinction can be found by Dewey in his contemplation about what constitutes a problem. He makes a difference between reflective problem solving and trial-and-error problem solving without a meaning (English, 2013: 78). For him, no problem-solving can have its transformative potential until the learner knows how to recognize a problem and starts to inquire about it, and by that, reflect upon it. Nevertheless, the biggest difference between Dewey's reflective problem and ill-defined problem lies in the core meaning of the reflection itself. For the latter one, it is unsure what kind of pedagogical aim the process of reflection has, other than to make learners "be successful during ill-defined, real-world problem solving." (Tawfik et al., 2015: 976). Following this thought, pedagogical aim is centered around "failure" and as implicated by it, and around "success". On the other hand, Dewey clearly sees the reflection as something transformative and existential - since being in the world for one means to experience how the world undergoes her/him. Therefore, pedagogical aim of a reflection is to understand relations to and about the world, to critically observe, make decisions and take actions in a democratic way.

\section{Remark on the Failure-based Learning designs}

Putting light on "ill-defined problems", problem-solving and failure-based learning designs seem like a good step for an empirical research on negativity of learning. In this way teachers could start creating an opening for an interruptive experience, without anyone being fully prepared for its outcome.

However, we can notice how the term negativity and its philosophical and criticalpedagogical potential is avoided, hence failure as a focal keyword emphasizes only the end stage of the reflective process, not its prereflective starting point. Putting 
problem and failure at the top of the learning process can cause overlooking of the prereflective aspect of experiencing negativity and the fact how it is crucial for learner's recognition and meaning of the problem itself. Learners do not necessarily have to fail to encounter Other and Otherness, to be alarmed by it and to subsequently, reflect upon it. The reflection comes before failure happens, although it doesn't need to happen. In that sense, further possibilities of both teacher and student experiencing negativity when it is not planned, "well or ill" defined or expected, are not mentioned in learning designs. Existing complexity of negative experience is something A. English warns about, it is included in the four forms of negativity by $\mathrm{H}$. Schluß and was remarked by J. Dewey himself as well: one's encounter with negativity doesn't have a pure cognitive, but an existential character (English, 2015).

Finally, except for Piaget's cognitive theory in learning, pedagogical implications of designs are not researched enough, especially in the aspect of the pedagogical aim behind them. Impasse driven learning, productive failure, failure-driven memory in case based reasoning and negative knowledge in workplace learning refer more to instructional aspect of learning-teaching process, for which main goal of negativity of learning is to indirectly enhance certain abilities by the learner, avoiding its immediate pedagogical transformative potential. In the following chapter, we will further discuss how this existential and transformative potential in ideas of negativity and discontinuity is related to notions of pedagogical subject.

\section{Distinction of traditional and critical theory}

If we are to discuss the idea of discontinuity as a way to pedagogically construct a critical-pedagogical subject, we first need to understand what critical-theoretical viewpoint is in its essence, so we can approach the idea of critical subject after that. The best place to start asking the question about critical-theoretical viewpoint is Max Horkheimer's classic essay "Traditional and critical theory" (Horkheimer, 2002), which gave us a deep notion of how critical theory in the modern sense should be articulated.

Regarding the essential distinction between traditional and critical theory, the central moment can be understood from this relatively simple formulation: "They [sciences] are moments in the social process of production, even if they are almost or entirely unproductive in the narrower sense." (ibid: 197) What Horkheimer aims at is the unconsciousness of sciences regarding their position in the totality of human being. Even if and when sciences are not directly "applied", but are "theoretical", such as pure mathematics, theoretical physics or philosophy, they are also productive forces of society. Not only that, but they are also influenced by other moments in the societies' material history. The total productive character of a societies' existence is such that all moments within this production influence one another. The central idea here is that sciences don't exist in their own isolated 
sphere, which is untouched by material context. They don't stand above lived experience and influence that experience in a linear way. Instead, they themselves are only moments of total material-historical production of being and meaning and these moments are in dialectical relationship.

Horkheimer explains this idea further: "The traditional idea of theory is based on scientific activity as carried on within the division of labor at a particular stage in the latter's development. It corresponds to the activity of the scholar which takes place alongside all the other activities of a society but in no immediately clear connection with them. In this view of theory, therefore, the real social function of science is not made manifest; it speaks not of what theory means in human life, but only of what it means in the isolated sphere in which for historical reasons it comes into existence. Yet as a matter of fact the life of society is the result of all the work done in the various sectors of production." (ibid: 197) The viewpoint of critically unexamined and assumed division of labor, seen as a positivistic "fact", enables the view of theory as something contained within itself, self-sufficient and complete. In this way, theory and science can be seen as something that exists per se and is not a moment in the whole of production of societies' existence. The necessity of looking at the totality of material existence, which produces sciences as only one of its moments can be seen, for example, in the fact that aims of science can not be deduced from science itself, while these aims also greatly influence the whole process of scientific work. The whole question of "why" in a larger sense and the question of meaning are absent from scientific work, when it's taken as a selfsufficient activity. These questions illustrate how moments outside of science itself determine science, just as well as how purely technically-minded science becomes when it is isolated from the whole of material production.

This division of science and human practice in a larger sense, of science and philosophy, of thinking and being produces two static contra-positions. In terms of what needs to be critically overcome in this division, the scientist is here a "savant" that is free of "tensions". The tensions are a product of dialectical dialogue between various moments of existence. If these moments become isolated from one another, they seem like self-sufficient areas of practice which operate on their own independent terms. This approach produces techno-science on the one hand and the world of practice where results of science can only be externally "applied" to it. There is no possibility of unity of theory and practice in this viewpoint.

On the other hand, "Critical thinking...is motivated today by the effort really to transcend the tension and to abolish the opposition between the individual's purposefulness, spontaneity, and rationality, and those work-process relationships on which society is built. Critical thought has a concept of man as in conflict with himself until this opposition is removed." (ibid: 210) This means that for the critical-theoretical approach human beings are alienated from themselves until they bring various modes of their existence into dialectical unity. The tension Horkheimer speaks about in this quote is an undialectical one - the tension in the 
sense of abstract opposition of various unconnected modes of being. The goal of critical theory is expressed here as removal of this alienation. The general way in which these alienations can be removed is to see all moments of being as produced and produced in a dialectical totality of material-historical practice. With this general position about critical-theoretical approach in mind, we can focus more specifically on the meaning of critical-pedagogical view on the idea of subject, so we can establish the kind of connection that discontinuity in learning has to it.

\section{Critical subject as self-production}

The central critical-pedagogical category is that of critical subject. This category is essentially connected to formation of the human being. Questions of: what kind of formation; with which purpose; and in which way we want, are essentially connected to the question of what human being as such is. So, the idea of human being encompassed within the idea of critical-subject is of central importance for pedagogical theory and practice.

"Critical thinking is the function neither of the isolated individual nor of the sum-total of individuals. Its subject is rather a definite individual in his real relation to other individuals and groups, in his conflict with a particular class, and, finally, in the resultant web of relationships with the social totality and with nature." (ibid: 211) It can be seen here that the critical subject for Horkheimer is a subject within his/her world. Isolated individual is a Cartesian subject which can find his/her own truth of being within him/herself through "traditional theory". This subject enabled by Descartes's philosophy finds his/her self-evidence through act of doubt and constitutes him/herself as thinking. After that fundamental act, this subject deduces the whole of being from this primary self-evidence. This is a subject that doesn't really need the outside world. But if human individuals really exist only as individuals within the world, then they can not be viewed as separate, independent, but only as dialectical moments. This is where the general critical-theoretical view can be observed in a particular sense. So, if we wish to understand the subject in a critical-theoretical sense, it's not sufficient to study one's inner thoughts, feelings and experiences. The critical subject still has its ability of self-production, it is still a free productive force, but the difference to the Cartesian subject is that here it isn't absolute, abstract, self-contained. However, it is also not a pure reaction to the outside world. Self-productivity within and in relation to other moments (determinations) of material history is the logic of critical-theoretical approach when it comes to the question of subject.

This subject is seen as a productive force, while at the same time the world itself is in flux of human production. This critical subject is self-produced just as the world is produced and this dialectic of production and that which is produced is the horizon in which critical subject can be found. But the distinction from positivism must not be forgotten and this distinction is in the character of the 
,produced': products here are not "facts", they are not nature, they are that which is formed by production. This whole dialectic reminds us of Hegel and the idea that the subject, if it is to exist, firstly it has to put itself into an object so (s)he can make him/herself a determined some-thing (Hegel, 1955). The whole of this object, which can be called the world, is clearly established as that which is produced by human practice - it is what Hegel calls the "objective spirit". But now, the subject needs to reflect itself back from the object into a new subject-objective dialectical unity if (s)he is not to stay in an alienated separation of subject as a place of mere possibility and object which exists only as a positivistic "fact". The subject and his/her world are in dialectical unity here and every moment in this unity is of a produced character.

This whole logic of subject-objective self-production comes from what I. Kant started with his reflections on the ideas of subject, thing per se and phaenomena (Kant, 1958) and was further developed by J. Fichte and his fundamental idea of the "productive act" (ger. Tathandlung), which is an act and a result of that act at the same time (in distinction from a "fact" (ger. Tatsache), a merely produced "thing"). (Fichte, 1974) As Fichte says: „So, the setting of self (ger. das Ich) by way of itself is its pure act. - The self sets itself and exists by this setting itself; and vice versa: the self is and sets its existence through its being. - It is at the same time that which acts and the product of this action; the action and that which is being produced through action; the act and the product are one and the same; and therefore: I am is a manifestation of a productive act (ger. Tathandlung)...] [translation: Z.K.]" (ibid: 46) What Fichte developed, based on Kant's ideas and overcoming his abstraction of thing per se (ger. Ding an sich), is the idea of a subject that encompasses the object as well, realising that there is no abstract and transcendent thing per se, but only things that are produced by the subject. Fichte saw further that the subject in itself is nothing that is "given", nothing that merely "is", but something that puts itself into existence by its action. This putting-itself-into-existence through action, this unity of action and being is what he called Tathandlung and what he put at the centre of his deduction as a first and absolute, non-conditional principle.

As Croatian philosopher Milan Kangrga put it: “...Fichte’s speculative identity of subject-object. This is what is manifested through his coinage 'Tathandlung' (productive act or self-awareness) which determines an act of production and a product in one and the same act)" (Kangrga, 1984: 45). The new moment here is "speculative identity of subject-object", which expresses that there is no fixed subject and no fixed object. There is only the setting and development of a subject through its action and at the same time and with this same action production of "world". But the world is never seen as an abstract object, as a "fact", as something "given", but as a product of action. Production and destruction, being and not-being are both part of the same speculative identity here.

This is the starting point for every modern anti-positivism and a central thing in trying to overcome alienation and separation of self and the world. Critical 
theory of so-called Frankfurt school of thinkers such as M. Horkheimer, T. Adorno, W. Benjamin etc. took on these fundamental ideas on subject, but revised through a thought of early K. Marx and developed them further. These ideas about the subject, a produced character of the world, history, theory and practice are the basis for critical theory and also critical pedagogy. Based on this ground, we can now ask our explicit pedagogical question: what is the connection of discontinuity in learning in its pedagogical sense with this critical subject seen as self-production? And also: is continuity in learning something detrimental for development of critical pedagogical subject?

\section{The idea of (dis)continuity and critical-theoretical view on pedagogical subject}

If we are to examine the idea of continuity in learning, this idea assumes a certain notion of knowledge. Only if knowledge is already complete and known in advance, then continuous learning is possible. Continuous learning proceeds in neat steps, without contradictions and with learning material that has no tension within itself. In order for this kind of process to be enabled, knowledge has to be seen as finished and perfect in advance. This is in strict contradiction with knowledge that is being built by subject-objective action of determination, reflection and further determination. This dialectical logic of circles of determination and reflection, or Bildung, are what J.F. Herbart called interest and saw as a central action and inner life of education (Herbart, 2015). In other words, since continuity implies an already finished character of knowledge, the pedagogical subject's relation towards content within this kind of learning is that of gathering what is already there. The attitude of understanding is still possible within this framework, but the productive element which is essential for the critical-pedagogical idea of the subject is absent. Understanding and internalizing the otherness of the world doesn't surpass the divide between self and the world within this attitude, because subject and object are separated. The knowledge as already finished and the content as already formulated are essentially outside of the subject. Knowledge in this sense is more of a product than production. This knowledge as a product can not escape its alienated form. As K. Marx says: “...the human being establishes him/herself as a being of genus in the very processing of the objective world. This production is his/her active generic life. Through this production nature appears as his/her product and his/her reality." (Marx, 1978: 252) With knowledge the situation isn't different if we look back at Fichte and see that every determination is an act of the subject as self-setting. The positivistic idea about the world and thing per se that exist in already complete and perfect knowledge, knowledge as a product, is in stark contrast to the idea of knowledge complementary with the critical notion of subject.

Continuity and the subject that experiences it in his/her pedagogical being does not open a spiritual space to experience real not-knowing. Self-aware not-knowing 
is that which pushes the subject towards self-production. In the stance of continuity and certainty, the world does not present itself to subject as activity of multiple and various subjects and tension between them, but as a calm world of products, as that which G. Debord calls by a unified name of "spectacle”: „Within spectacle, a part of the world presents itself to the world and is overpowering in the relation to the world. The spectacle is only a general language of this separation." (Debord, 1999: 46) What Debord means by this is that spectacle is the final stage of alienation as separation of products from productive actions that produce them. Historically first alienation came in the form of having over being and further development, according to Debord is further abstraction of image over product. In other words: "The spectacle is capital in a stage of accumulation in which it becomes an image." (ibid: 47) In the world of aesthetic and cultural experience T. Adorno sees the same thing in complete absence of conflicts: "Mass culture treats conflicts but in fact proceeds without conflict. The representation of living reality becomes a technique for suspending its development and thus comes to occupy that static realm which revealed the very essence of variété." (Adorno, 1991: 71) To sum up, continuity as a character of learning goes hand in hand with idea of knowledge as something finished, with separation of object and subject and with alienated character of objects, which encompasses all forms of pedagogical content - whether it's knowledge or cultural experiences in the widest sense of the word.

\section{Final word}

Throughout the paper, besides getting acquainted with the notion of discontinuity in learning as delivered by A. English, we explored its connection to pedagogical origins and discussed its critical-philosophical potential, for the sake of putting it into the perspective of pedagogical context. We could notice that the notion of discontinuity in learning is quite new to the present pedagogical science, but also how it has been embedded in the pedagogical heritage for a long time now. We could see what importance the negativity in the process of learning has - the experience of a gap, perplexity, doubt, otherness - for the subjective-objective self-production of the pedagogical subject, in order for her/him to take part in the dialectical never ending process of self-transformation, process of being and not being, knowing and not knowing, producing and being the product, all happening at the same time. Furthermore, this also pinpointed the necessity for pedagogical concepts to be critically observed with the help of philosophy, something that is nowadays in pedagogical context often avoided. The notion of Discontinuity in learning is something that could keep our future pedagogical theory and practice from losing the true pedagogical purpose, and even its implementation into the learning environment is yet to be explored, this paper hopes to be, at least, a good way to start. 


\section{Bibliography}

Adorno T. (1991). The culture industry. London: Routledge.

Benner D. (2005). Einleitung über pädagogisch relevante und erziehungswissenschaftlich fruchtbare Aspekte der Negativität menschlicher Erfahrung. „Zeitschrift für Pädagogik", nr 49, Beiheft, s. 7-21.

Debord G. (1999). Društvo spektakla. Zagreb: Arkzin.

English A. (2013). Discontinuity in learning: Dewey, Herbart and Education as Transformation. New York: Cambridge University Press.

Fichte J.G. (1974), Osnova cjelokupne nauke o znanosti. Zagreb: Naprijed.

Hegel G.W.F. (1955). Fenomenologija duha. Zagreb: Kultura.

Herbart J.F. (2015). The science of education, its general principles deduced from its aim and. The aesthetic revelation of the world. London: FB \& Ltd.

Horkheimer M. (2002). Traditional and critical theory. W: Critical theory: Selected essays. New York: Continuum, s. 188-244.

Kangrga M. (1984). Praksa, vrijeme, svijet. Zagreb: Nolit.

Kant I. (1958). Kritika čistog uma, Zagreb: Kultura.

Marx K., Engels. F. (1978). Rani radowi. Zagreb: Naprijed.

Schluß H. (2005). Negativität im Unterricht. „Zeitschrift für Pädagogik”, nr 49, Beiheft, s. 182-196.

Song y., Kapur M. (2017). How to flip a classroom - „Productive Failure or Traditional Flipped Classroom”. Pedagogical design? „Educational Technology \& Society”, nr 20 (1), s. 292-305.

Tawfik A., Andrew Rong H., Choi Ikseon. (2015). Failing to learn: towards a unified design approach for failure-based learning. „Educational Technology Research and Development”, December 2015, vol. 63, nr 6 (December 2015), s. 975-994. 